\title{
Occurrence of Obesity in Patients with Cardiovascular Diseases
}

\section{Zamboriova (Maria Zamboriova)1, L. Dimunova (Lucia Dimunova)ำ J. Michalkova (Jana Michalkova)1', J. Buckova (Jana Buckova)², I. Nagyova (Iveta Nagyova)²}

${ }^{1}$ Department of Nursing, Faculty of Medicine Pavol Jozef Safarik Original Article University in Kosice, SK.

${ }^{2}$ Department of Social and Behavioral Medicine, Faculty of Medicine Pavol Jozef Safarik University in Kosice, SK.

\section{E-mail address:}

maria.zamboriova@upjs.sk

\section{Reprint address:}

Maria Zamboriova

Faculty of Medicine Pavol Jozef Safarik University in Kosice

Department of Nursing

Tr. SNP 1

04001 Kosice

Slovakia

Source: Clinical Social Work and Health Intervention

Volume: 12

Issue: 5

Pages: 95 - 99

Cited references: 14

\section{Reviewers:}

Andrea Shahum

University of North Carolina at Chapel Hill School of Medicine, USA

Vitalis Okoth Odero

Catholic University of Eastern Africa, Nairobi, KE

\section{Keywords:}

Cardiovascular Diseases. Obesity. Lifestyle.

\section{Publisher:}

International Society of Applied Preventive Medicine i-gap

CSWHI 2021; 12(5): 95 - 99; DOI: 10.22359/cswhi_12_5_14 CC Clinical Social Work and Health Intervention

\section{Abstract:}

Objective: The aim of this research is to identify behavioral risk factors in patients with cardiovascular diseases with a focus on obesity.

Design: Descriptive study.

Participants: The sample group consisted of 878 patients with ischemic heart disease.

Methods: Clinical, laboratory parameters and a questionnaire focused on identifying behavioral risk factors of one's lifestyle. Data processing through descriptive and inductive statistics.

Results: The mean BMI is 29.39 ( \pm SD 4.69). The results 
show that $355(40.2 \%)$ patients have obesity and we identified overweight as a precursor to obesity in $377(42.93 \%)$ patients. We found deficiencies in behavioral risk factors (smoking, alcohol consumption, nutrition, physical activity) in all patients. A significant relationship was confirmed between smoking, alcohol consumption and obesity.

Conclusion: The results of our research suggest that there is a need to improve primary and secondary prevention in patients, healthcare professionals and government policy.

\section{Introduction}

Cardiovascular diseases (CVD) belong among diseases with the highest morbidity and mortality rate in Slovakia. According to current medical knowledge, a great number of risk factors contribute to the origination and development of cardiovascular diseases, and it is true that the more risk factors one has, the sooner the disease develops and it develops faster. An increased weight is associated with: increased risk of overall morbidity and mortality from CVD; with increased blood pressure; increased likelihood of diabetes (1).

The summary of ESC recommendations also states that overweight and obesity are associated with a risk of death from CVD (2). In most cases, obesity is a multifactorial determined disease, in which the interaction of environmental factors and genetic predispositions leads to a positive energy balance that results in excessive accumulation of adipose tissue. It is usually defined by body mass index (BMI - weight in $\mathrm{kg} /$ height in $\mathrm{m} 2$ ) (3). Obesity is one of the behavioral risk factors for the origination and development of cardiovascular diseases. Other behavioral risk factors include: smoking; poor eating habits; alcohol consumption; insufficient physical activity, and excessive stress. The aim of our research was to identify behavioral risk factors in patients with cardiovascular diseases. We focused on obesity as one of the most important risk factors and we also monitored the relationship between obesity and selected risk factors.

\section{Methodology}

The sample group consisted of 878 patients with ischemic heart disease (IHD), hospitalized in a specialized cardiovascular medical facility (VUSCH, a.s.) in Kosice. The sample was selected on the basis of the following criteria: confirmed ischemic heart disease; patients indicated for selective coronary angiography; patients after coronary angiography or coronary angioplasty; patients with positive findings from coronary angiography. As a method of data collection, we used clinical, laboratory parameters and a questionnaire of our own design, in which we focused on the identification of behavioral risk factors of one's lifestyle (smoking, alcohol consumption, eating habits, physical activity). The research was carried out in a specialized medical facility the East Slovak Institute of Cardiovascular Diseases, a.s. Kosice (VUSCH, a.s.). The study protocol was approved by the Ethics Committee of the Faculty of Medicine, P. J. Safarik University in Kosice (approval no. 115/2011), and all patients gave written informed consent before participating in the study. To evaluate the data, methods of descriptive and inductive statistics (Pearson's Chi-square test) were used. Data were processed in SPSS 25.0.

\section{Results}

The sample group consisted of 878 patients with IHD. The mean age of the patients was $57.81 \pm$ SD 7.58 years. The age range of the research group was from 24 to 75 years. Of the total number of respondents, $60 \%$ were men $(\mathrm{n}=$ $527) ; 40 \%$ were women $(n=351)$. In terms of clinical and laboratory parameters, we found the following values: mean systolic blood pressure: 137.03 ( \pm SD 18.80); mean diastolic blood pressure: 83.39 ( \pm SD 11.47); mean total cholesterol: 4.92 ( \pm SD 1.23); mean HDL cholesterol: 1.24 ( \pm SD 0.61); mean LDL cholesterol: 2.92 ( \pm SD 1.69); mean triglycerides: 1.98 ( \pm SD 1.51); mean blood glucose: 6.76 ( \pm SD 4.22). The values of obesity represent the calculation of BMI index that is above 30. Mean BMI of the sample is 29.39 ( \pm SD 4.69$)$. The maximum BMI value of the respondents was 51.99 ; the minimum value was 16.90. BMI below 25 (normal weight) 
had $16.62 \%(\mathrm{n}=146)$ of respondents (Table 1$)$. The results show that $355(40.2 \%)$ patients have obesity and we identified overweight as a precursor to obesity in 377 (42.93\%) patients.

Table 1 BMI index values $(n=878)$

\begin{tabular}{|l|c|c|}
\hline Body Mass Index (BMI) & $\mathbf{n}$ & $\%$ \\
\hline BMI underweight (<18.5) & 11 & 1.25 \\
\hline BMI normal weight (18.5-24.9) & 135 & 15.37 \\
\hline BMI overweight (25-29.9) & 377 & 42.93 \\
\hline BMI obesity (30-34.9) & 249 & 16.9 \\
\hline BMI extreme obesity (>35) & 106 & 12.07 \\
\hline
\end{tabular}

\section{Lifestyle behavioral risk factors}

Smoking is identified as one of the most serious risk factors for cardiovascular diseases. In the monitored group, $46.2 \%(n=405)$ were exsmokers; $40.9 \%(n=359)$ were absolute nonsmoker; $12.9 \%(n=114)$ - the smallest number were smokers.

As for the alcohol consumption, the most common response was: occasional alcohol consumption in $59.6 \%(\mathrm{n}=523)$; abstinent in $37.1 \%$ $(\mathrm{n}=326)$; regular alcohol consumption in $3.3 \%$ $(n=23)$ of respondents. We were also interested in what kind of alcohol respondents consume. The answer "all types of alcohol" had the highest share of $47.5 \%(n=253)$; it was followed by hard liquor with $20.7 \%(\mathrm{n}=113)$; wine $15.5 \%(\mathrm{n}=$ $86)$; beer $14.0 \%(\mathrm{n}=78)$; whiskey and brandy $1.3 \%(n=12)$; the lowest share had other alcohol with $1 \%(\mathrm{n}=10)$.

Table 2 lists the findings related to patients' nutrition. Respondents generally consume fruit and vegetables, which we can evaluate positively. They should limit the consumption of smoked meat products. When asked what kind of bread they preferred, we found that a consumption of white bread dominated in $57.4 \%(n=494)$ of respondents; $30.9 \%(n=266)$ of asked patients preferred brown bread; consumption of both white and brown was reported by $11.7 \%(n=118)$ of respondents.

Physical activity is an important part of adherence to the treatment of patients with cardiovascular diseases. In the monitored group: $74.5 \%$ $(n=650)$ of patients answered that they preferred walking; $22.1 \%(n=195)$ of patients do not exercise; $3.4 \%$ (33) of respondents practice sport regularly.

Overall, we were interested if there was a relationship between obesity and significant risk factors such as smoking and alcohol consumption. A significant relationship was confirmed between obesity and smoking in the sense that exsmokers and non-smokers are more obese than smokers $\left(x^{2}=6.207 ; p=0.045\right)$. Similarly, we found a statistically significant relationship between obesity and alcohol consumption. Patients who consume alcoholic beverages occasionally have a higher incidence of obesity than patients who are abstinent or consume alcohol regularly $\left(\mathrm{x}^{2}=9.901 ; \mathrm{p}=0.007\right)$.

\section{Discussion and Conclusion}

Obesity or overweight are currently a global public health problem that is reaching epidemiological proportions in economically developed countries. According to OECD indicators (4), overweight and obesity occurrence in Slovakia is below the average of the EU countries. About $16 \%$ of the population over 15 years of age is obese in Slovakia. According to the analysis of

Table 2 Nutrition of patients with IHD ( $\mathrm{n}=878)$

\begin{tabular}{|l|c|c|c|c|}
\hline Consumption & Fruit $\mathbf{n}(\%)$ & Vegetables $\mathbf{n}(\%)$ & Sweets $\mathbf{n}(\%)$ & Smoked products $\mathbf{~ ( \% ) ~}$ \\
\hline daily & $436(49.7)$ & $359(40.9)$ & $226(26.1)$ & $75(8.7)$ \\
\hline 2-3 times a week & $315(35.9)$ & $400(45.6)$ & $257(29.7)$ & $369(42.9)$ \\
\hline once in a week & $81(9.2)$ & $82(9.3)$ & $202(23.4)$ & $241(28.0)$ \\
\hline seldom & $42(4.7)$ & $35(4.0)$ & $177(19.0)$ & $169(17.6)$ \\
\hline never & $6(0.5)$ & $2(0.2)$ & $16(1.8)$ & $24(2.8)$ \\
\hline
\end{tabular}


the latest available data of clients of Counseling Centers for Health Protection and Support (i.e. Health Counselling) of the Slovak Republic Public Health Authority, in the area of occurrence of one of the risk factors of cardiovascular diseases: $50.3 \%$ of clients had normal weight; overweight was found in $29.1 \%$ of clients; obesity in $18 \%$ of clients. Those were mainly age groups over 35 years in men: over 45 years in women (5). In the monitored group, we also recorded a high incidence of obesity (40.2\%) and overweight $(42.93 \%)$ in patients with CVD. The presence of other risk factors such as smoking, poor eating habits, alcohol consumption and insufficient physical activity indicate shortcomings.

The results of our research point to the fact that it is necessary to strengthen primary and secondary prevention in patients with cardiovascular diseases. The most important measure to prevent obesity is to control body weight and maintain a BMI of $20-25.0 \mathrm{~kg} / \mathrm{m} 2$, waist circumference $<102 \mathrm{~cm}$ in men: $<88 \mathrm{~cm}$ in women, ideally $<94 \mathrm{~cm}$ in men; $<80 \mathrm{~cm}$ in women $(2,6,7)$. As pointed out by several authors $(8,9,10,11,12)$, it is possible to use several options, e.g. creation of educational centers or more effective administering of nurses' educational competences in practice. In treatment and nursing care, multidisciplinary cooperation (13) and effective application of communication skills of nurses and physicians in relation to the patient are necessary. Emphasis is placed on the attitude towards health and on responsible behavior, such as: regular weight control; adherence to dietary recommendations; regular physical activity; participation in preventive health check-ups (14). Overweight and obesity is an issue of interest at the national level as well as in the international context.

\section{Declaration of conflicting interests}

The author(s) declared no potential conflicts of interest with respect to the research, authorship and/or publication of this article.

\section{Acknowledgements}

This work was supported by the Slovak Research and Development Agency under contract APVV-15-0719.

\section{References}

1. STUDENCAN M (2014) Acute coronary syndrome. Bratislava: Media Group, s.r.o. 2014. 235p.

2. PIEPOLI MF, HOES AW, AGEWALL $S$ et al. (2016) ESC Scientific Document Group. (2016). European Guidelines on cardiovascular disease prevention in clinical practice: The Sixth Joint Task Force of the European Society of Cardiology and Other Societies on Cardiovascular Disease Prevention in Clinical Practice. Eur Heart J, 2016; 1;37(29):2315-2381.

doi:10.1093/eurheartj/ehw106.

3. BELOVICOVA M, VANSAC P (2019) Selected aspects of medical and social care for long-term ill persons. Towarzystwo Slowakow w Polsce. Krakow, 2019. 153p.

4. OEDC (2016) Health and healthcare in Slovakia in the European comparison in 2016. Analyzes and comments based on report data OECD: Health at a Glance: Europe. 2016. [online]. [cit. 2021-01-16]. Available in: http://cpldz.sk/2017/01/18/zdravie-azdravotnictvo-na-slovensku-v-europskomporovnani-v-roku-2016.

5. KONTROSOVA S (2016) Health protection and promotion counseling centers in SR 2016. [online]. 2016. [cit. 2019-10-02]. Available in: http://www.uvzsr.sk/docs/info/ podpora /SR_PZ_2016.pdf.

6. MACH F, BAIGENT C, CATAPANO AL et al. (2020) ESC Scientific Document Group. 2019 ESC/EAS Guidelines for the management of dyslipidaemias: lipid modification to reduce cardiovascular risk. Eur Heart J, 2020; 41(1):111-188. doi: 10.1093/eurheartj/ ehz455.

7. WILLIAMS B, MANCIA G, SPIERING W et al. (2018) ESC/ESH Guidelines for the management of arterial hypertension. In $E u$ ropean Heart Journal, 2018; 39(33): 30213104.

8. KRISTOVA J, BACHRATA Z, SLEZAKOVA Z, MIKLOVICOVA E (2021) Implementation of telenursing in the Slovak Republic. Nursing in the 21 st Century. 2021; 20(3): 216-220. doi:10.2478/pielxxiw-20210028 .

9. GRESS HALASZ B, MAJERNIKOVA L, OBROCNIKOVA A, HUDAKOVA A, VO- 
JTEKOVA M (2020) Developing the advanced practice nursing role in Slovakia: Perception, education, and practice [published online ahead of print, $2020 \mathrm{Jul} 29$ ]. J Am Assoc Nurse Pract, 2020;10.

10. CERVENY M, SIAKI L A, MCGEE P, KILIKOVA M (2019) Perception of European nurses of culturally-appropriate health care a cross-sectional study. Med Og Nauk Zdr, 2019; 25(1): 27-32. https://doi.org/10.26444 /monz/102392.

11. HULKOVA V (2016) Standardization in Nursing. Martin: Osveta; 2016. 232 p.

12. SOVARIOVA SOOSOVA M, HREHOVA J (2014) The effect of education on lifestyle changes and metabolic syndrome components. Cent Eur J Nurs Midw. 2014; 5(4): 161-168. http://doi.org/10.15452/CEJNM. 2014.05.0012.

13. POLIAKOVA N, MATISAKOVA I, GERLICHOVA K, HAVIAROVA K (2020) Diabetic neuropathy and diabetic foot syndrome in the context of hyperbaric oxygen therapy. Zdravotnicke listy, 2020; 8(1): 13-19.

14. BARTOSIEWICZ A, LUSZCZKI E, NAGORSKA M, OLEKSY L, STOLARCZYK A, DEREN K (2021) Risk Factors of Metabolic Syndrome among Polish Nurses. 2021, Metabolites, 2021; 11(5): 267 doi:10. 3390/metabo11050267. 